\title{
Determinants of Helminth Infection in a Subterranean Rodent, the Cape Dune Mole-Rat (Bathyergus suillus)
}

\author{
Heike Lutermann and Nigel C. Bennett, Department of Zoology and Entomology, Mammal Research Institute, University of Pretoria, Pretoria \\ 0002, South Africa. e-mail: hlutermann@zoology.up.ac.za
}

ABSTRACT: The helminth fauna of the largest bathyergid, the Cape molerat (Bathyergus suillus) was studied throughout an entire calendar year. The species richness encountered was low, with only 3 species of nematodes (Longistriata bathyergi, Mammalakis macrospiculum, and Trichostrongylus sp.) and 2 species of cestodes (Taenia sp. and Rodentolepis sp.). At less than $10 \%$, the prevalence for all helminths species was similarly low and may be a result of the solitary lifestyle and the subterranean habitat exploited by this rodent. Clear seasonal patterns were apparent for the most common nematode (L. bathyergi), and prevalence and abundance were highest among non-pregnant females compared to males and pregnant females. Dispersal patterns associated with the mating system of the host could explain this pattern. In contrast, the prevalence of the most common cestode (Taenia sp.) was neither determined by season nor host sex, suggesting that foraging habits may constantly expose B. suillus to this parasite.

Although parasites are ubiquitous, individuals within host populations often show marked variation in parasite prevalence and abundance, and the parasite distribution is highly skewed (Poulin, 2007). Such heterogeneities can be caused by both intrinsic and extrinsic factors, which determine the exposure and susceptibility of hosts to parasites. Effects of intrinsic factors such as host sex have been reported for many vertebrate species (Poulin, 1996; Klein, 2004). Gender bias has been alternatively linked to body size differences (Moore and Wilson, 2002), differences in space use patterns (e.g., Scantlebury et al., 2010), and the immunosuppressive effects of androgens (Folstad and Karter, 1992; Klein, 2004). Extrinsic factors such as rainfall and temperature, on the other hand, often act on the parasite directly, resulting in variation in the spatial and temporal distribution of parasites (Poulin, 2007). Such extrinsic factors and, as a consequence, the distribution of parasites often differ between habitats, and, accordingly, habitat use can determine the exposure of hosts to parasites (Froeschke et al., 2010).

It has repeatedly been noted that the subterranean niche of fossorial rodents may limit their exposure to parasites, and this has been linked to the low parasite species richness encountered in a number of subterranean rodents (Gardner, 1985; Hafner et al., 2000; Rossin and Malizia, 2002; Rossin et al., 2010). Rodents from a range of families have adapted to a subterranean lifestyle, and, despite their diverse origin, they show remarkable similarities with respect to morphology, physiology, and basic life history traits. Their cryptic lifestyle has contributed to the paucity of information about their parasite fauna. However, efforts have been made, and studies on the North American geomyids, the South American octodontids, as well as the European spalacines have reported a number of cestodes, nematodes, and coccidian parasites for these rodents (Gardner, 1985; Hafner et al., 2000; Rossin and Malizia, 2002; Rossin et al., 2010). Most of these studies are of a taxonomic nature (Rossin and Malizia, 2002; Rossin et al., 2010). The southern African bathyergids, or mole-rats, are another very specious family of subterranean rodents (Bennett and Faulkes, 2000). Although bathyergids are well studied with respect to their ecology and reproductive physiology, we have little knowledge of their endoparasites beyond that gleaned from opportunistic sampling (de Graaff, 1964). Unlike most subterranean rodents, this family consists mainly of social species, and only 3 solitary genera with 4 species are known (Bennett and Faulkes, 2000). Recent taxonomic studies of the endoparasite fauna of solitary mole-rats are limited to 1 species, the silvery mole-rat, Heliophobius argenteocinereus, from a small sample size (Tenora et al., 2003; Modrý et al., 2005). The aim of the current study was to provide information on the helminth parasites of another solitary

DOI: $10.1645 / G E-3024.1$ bathyergid, the Cape dune mole-rat (Bathyergus suillus), and to assess the effects of host sex and reproductive condition as well as season, i.e., capture month, on endoparasite prevalence and abundance. Bathyergus suillus is the largest bathyergid species, and the body mass of adult males can exceed $2 \mathrm{~kg}$ (Skinner and Chimimba, 2005); they are regularly used as a protein source by humans. This species is endemic to South Africa and inhabits predominantly sandy soils along the coast and on river banks close to the coast in the Western and Eastern Cape Province. The diet of B. suillus consists mainly of aerial vegetation that it pulls into its tunnels from below (Skinner and Chimimba, 2005).

Parasite samples were obtained from mole-rats captured by professional mole catchers at Cape Town International Airport, Cape Town, South Africa $\left(33^{\circ} 58^{\prime} \mathrm{S}, 18^{\circ} 37^{\prime} \mathrm{E}\right)$, as part of an eradication program conducted in conjunction with the University of Cape Town. A total of 344 animals were captured during the period from March 2003 to January 2004. Animals were caught on a daily basis with the use of modified vice traps (Vasatrap, Observatory, Cape Town, South Africa). Three-millimeterthick rubber strips were wrapped around both serrated edges of the trap and secured in place with cable ties. Traps were checked at regular intervals, and captured animals were killed with an overdose of chloroform. The animals were sexed and weighed and the body length (excluding the tail) measured. The abdominal cavity was opened, and the intestinal tract removed and stored in $70 \%$ ethanol until dissected. For females, the reproductive condition was assessed by uterine inspection and the presence of embryos noted. Intestinal tracts were separated in the functional sections (stomach, small intestine, caecum, and large intestines) and dissected separately. The content was examined using a stereomicroscope. Parasites were counted and stored in $70 \%$ ethanol until identification by the Royal Veterinary College, London, U.K.

We employed generalized linear models (GLMs) with parasite prevalence and abundance, respectively, as dependent variable. The factors month, sex class, and body length were included as independent variables in all models. Since only 4 hosts were sampled in June, while otherwise the minimum sample size per mo was 15 (mean \pm SE: $34.0 \pm$ 3.97 ), we pooled the data for June and July for analyses. To allow comparisons with the results obtained by Rossin et al. (2010) for Ctenomys species, we defined 3 sex categories: males, non-pregnant females, and pregnant females. However, unlike Rossin et al. (2010), we did not use body condition as it was confounded for pregnant females, and, consequently, it differed significantly between pregnant and nonpregnant females $(t=-4.484, \mathrm{df}=171, P<0.0001)$. Since body mass was significantly correlated with body length in non-pregnant individuals $\left(R_{S}=0.911, \mathrm{n}=283, P<0.0001\right)$, we included body length as a variable for the analyses. Separate models were created for different parasite species, assuming a binomial error distribution with a log-link function when considering prevalence. Parasite prevalence and abundance were evaluated only for species with a prevalence of greater than $5 \%$. A GLM with a quasi-Poisson error distribution and a log-link function was employed when analyzing the effects of our independent variables on parasite abundance. Initially we included interaction terms in the models; however, these proved to be non-significant, and, consequently, only the main effect model will be reported. Results are given as means $\pm \mathrm{SE}$.

A total of 344 individuals (181 females, 161 males, 2 of unknown sex) were sampled from March 2003 until January 2004. Of all females assessed, 50 were pregnant. The animals showed a marked sexual dimorphism, with females being significantly lighter (non-pregnant, $\mathrm{n}=$ $123,667.2 \pm 241.5 \mathrm{~g})$ than males $(\mathrm{n}=160,949.8 \pm 426.0 \mathrm{~g}, Z=-5.64, P$ $<0.0001)$. Similarly, males $(\mathrm{n}=160,320.9 \pm 40.1 \mathrm{~mm})$ had significantly greater body lengths than females $(\mathrm{n}=179,229.3 \pm 33.8 \mathrm{~mm}, Z=-5.62$, $P<0.0001)$. 
TABLE I. Summary of the parasite species and their infection characteristics in Bathyergus suillus $(\mathrm{n}=344)$.

\begin{tabular}{|c|c|c|c|c|}
\hline Longistriata bathyergi & Small intestine & 8.7 & 0.85 & $0-44$ \\
\hline Mammalakis macrospiculum & Large intestine and caecum & 1.5 & 0.02 & $0-4$ \\
\hline Taenia sp. & Abdominal cavity & 7.6 & - & - \\
\hline Rodentolepis sp. & Small intestine & 0.9 & 0.01 & $0-2$ \\
\hline
\end{tabular}

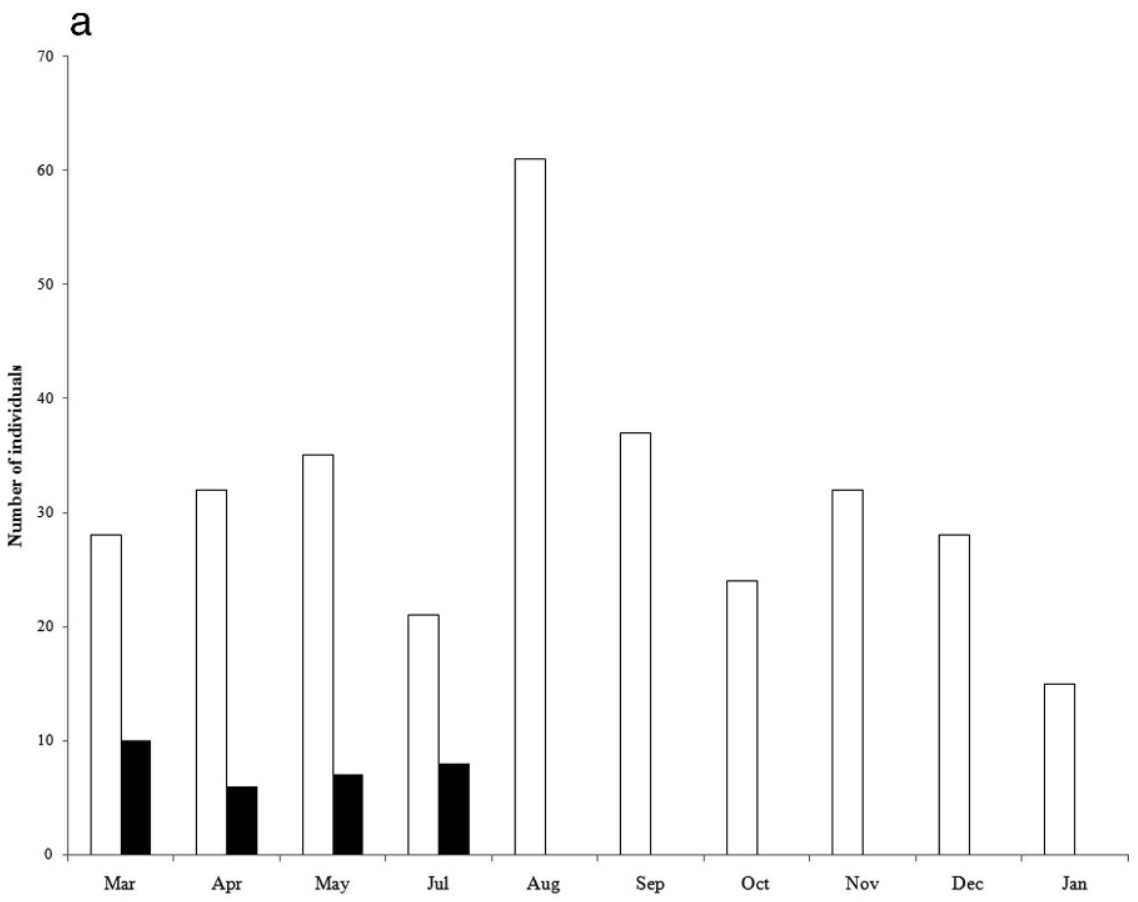

b

Figure 1. Seasonal variation in the prevalence of (a) Longistriata bathyergi and (b) Taenia sp. from March 2003 until January 2004. Displayed are the number of individuals for each category and month. Open and filled bars indicate uninfected and infected individuals, respectively.

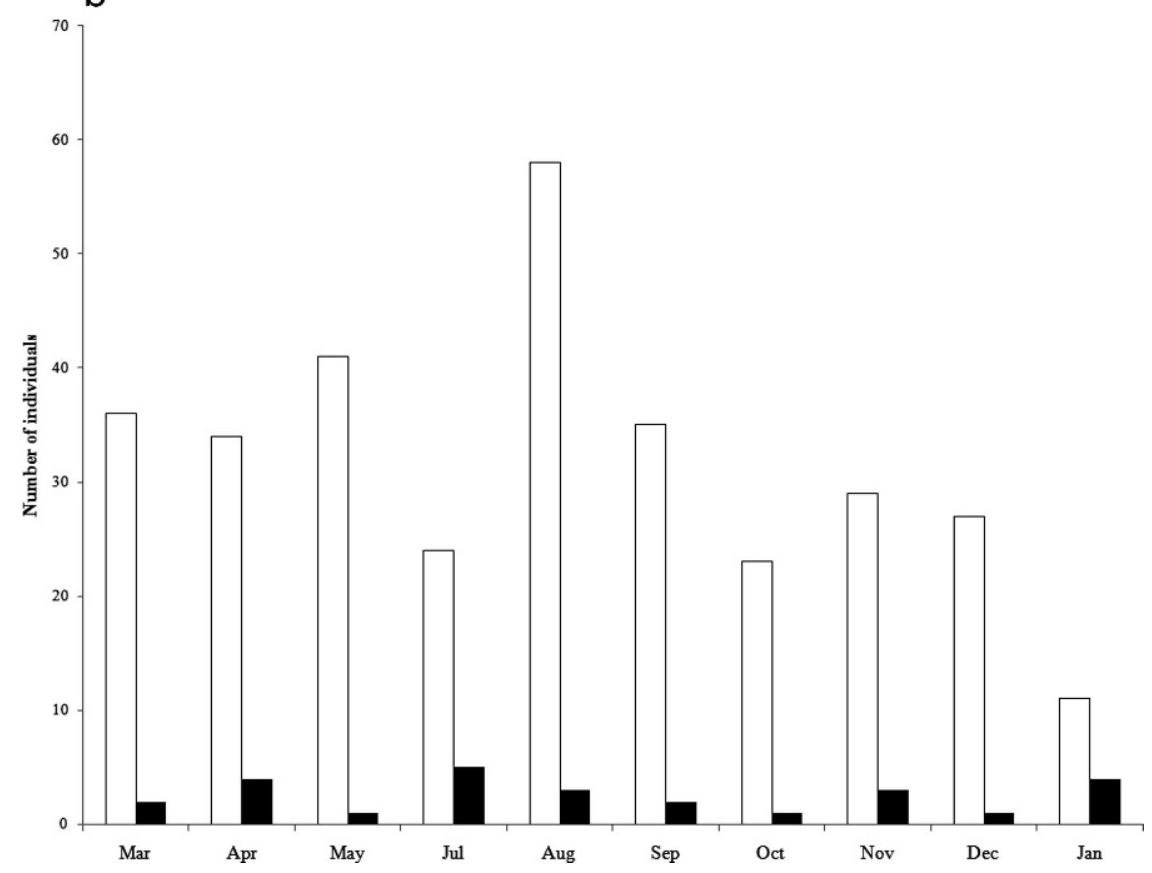




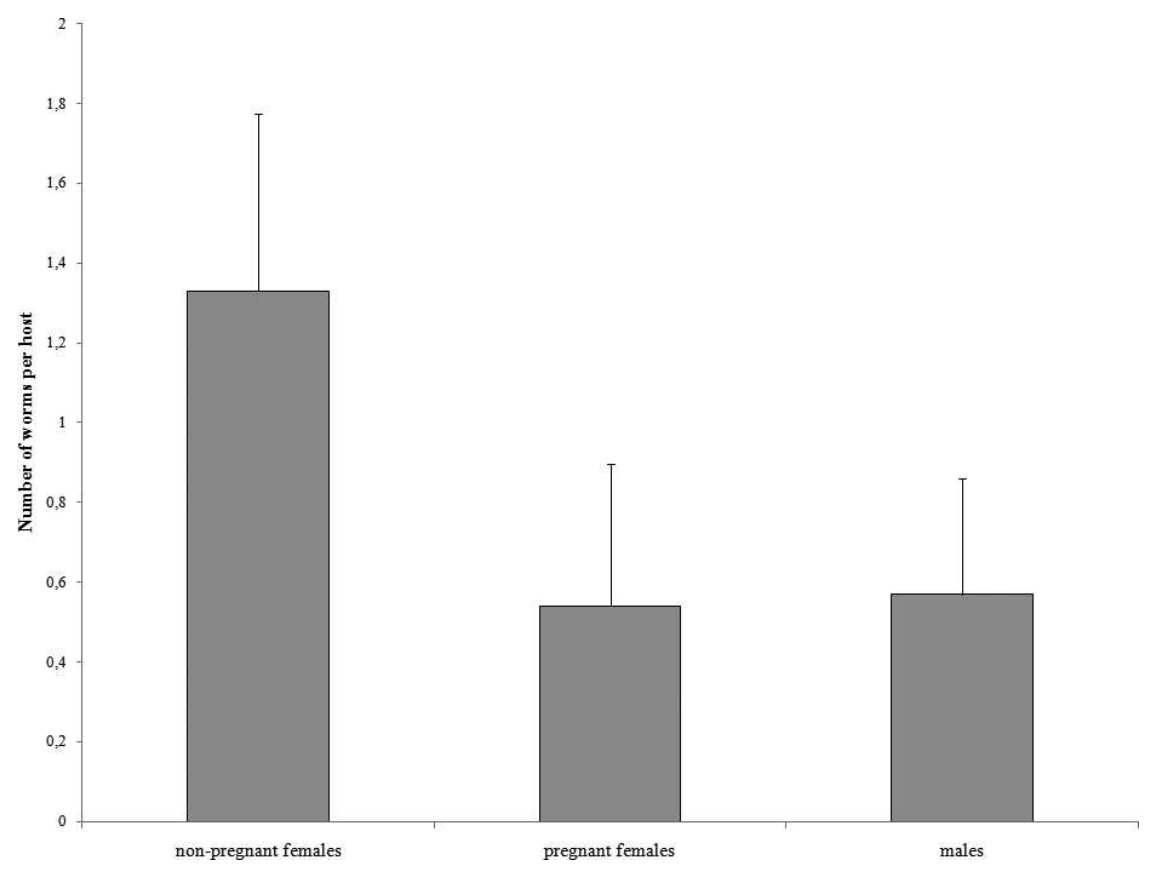

Figure 2. Mean $( \pm \mathrm{SE})$ number of L. bathyergi per host as a function of host sex and reproductive condition.
The animals examined were infected with 5 helminth species (Table I). The most common parasites found were the nematode Longistriata bathyergi with a prevalence of $8.7 \%$ and an abundance of $0.85( \pm 0.22)$ and the cestode Taenia sp. with a prevalence of 7.6\%. Only strobilocerci were encountered for the latter species. As such, strobilocerci may have occurred in other tissues not accessible for this study; accordingly, we only recorded prevalence for this parasite. Both L. bathyergi and Mammalakis macrospiculum have to date been reported only for B. suillus (Ortlepp, 1939; Inglis, 1991), while the remaining helminths belong to genera that are cosmopolitan in their distribution.

The prevalence of $L$. bathyergi was significantly affected by mo $\left(\chi^{2}=\right.$ 57.3 , df $=10, P<0.0001)$, with infection only being observed from March to July (Fig. 1a). Nematode prevalence did not differ significantly between the sex classes $\left(\chi^{2}=2.6, \mathrm{df}=2, P=0.279\right)$. However, the probability of infection decreased significantly with increasing body length $\left(\chi^{2}=17.9\right.$, df $=1, P<0.0001)$. The abundance of $L$. bathyergi varied significantly throughout the year $\left(\chi^{2}=465.8, \mathrm{df}=9, P<0.0001\right.$; Fig. 1a). Longistriata bathyergi abundance differed significantly between the sexes $\left(\chi^{2}=41.1\right.$, df $=1, P<0.0001)$ and was greater for non-pregnant females compared to pregnant females or males (Fig. 2). The abundance of L. bathyergi was also significantly negatively correlated with body length $\left(\chi^{2}=231.1, \mathrm{df}=\right.$ $1, P<0.0001)$.

The prevalence of Taenia sp. did not differ significantly between mo $\left(\chi^{2}\right.$ $=14.7, \mathrm{df}=10, P=0.142)$, and infected animals were present throughout the year (Fig. 1b). Cestode prevalence did not differ significantly between sex classes $\left(\chi^{2}=2.5\right.$, df $\left.=2, P=0.284\right)$. Similarly, infection with Taenia sp. was not significantly correlated with body length $\left(\chi^{2}=2.1\right.$, df $=1, P=$ $0.112)$.

Despite the large number of animals sampled for this study, the parasite species richness as observed was rather low. This finding is in accordance with observations from other subterranean rodents and has been attributed to the limited parasite exposure in the subterranean habitat, as well as the solitary lifestyle of most species studied to date (Hafner et al., 2000; Rossin et al., 2010). Nonetheless, the sedentary habits of subterranean rodents have previously been cited as cause for their fairly high helminth prevalence (Rossin and Malizia, 2002; Rossin et al., 2010). The low endoparasite prevalence encountered in our study species does not fit this pattern. This may be attributed to the sandy soils exploited by $B$. suillus that could be less favorable habitat for helminths. In addition, the uneven distribution of such soils causes B. suillus to venture above ground comparatively frequently in search of new patches to exploit (Bennett and Faulkes, 2000), and this, in turn, may reduce parasite recruitment. While these hypotheses are currently rather speculative, they merit further attention in future studies.

The distribution of L. bathyergi showed clear seasonal patterns, being present only from late summer until mid-winter. This period coincides with the onset of the rainy winter season and the mating season of $B$. suillus (Hart et al., 2006). Accordingly, increases in nematode prevalence and abundance may be a result of increases in ranging behavior when searching for mates. Alternatively, but not mutually exclusive, the comparatively mild climatic conditions (warm and moderate rainfall) may be conducive for the propagation of the parasite. Since the life cycle of $L$. bathyergi is unknown, we can only speculate in how far these factors may contribute to the observed pattern.

In contrast, the prevalence of Taenia sp. did not vary with season and was generally low throughout the year. These different patterns may be linked to the different life cycles of the parasites as taeniids have an indirect cycle. Hence, abiotic, as well as biotic, factors acting on the parasite and both intermediate and final host are likely to contribute to the observed pattern. Bathyergus suillus feeds on aboveground vegetation that it pulls below the surface and may acquire the parasite through this route. Despite the marked sexual dimorphism of B. suillus, there was no evidence for a sex bias in the prevalence of either of the 2 helminths with a prevalence greater than $5 \%$, and the abundance of $L$. bathyergi was greatest for non-pregnant females. This finding is in stark contrast with the commonly found pattern of male-biased parasite prevalence and abundance found in a number of mammals (Poulin, 1996; Moore and Wilson, 2002; Klein, 2004). However, in 2 other subterranean rodents, Ctenomys talarum and $C$. australis, Rossin et al. (2010) found that nonpregnant females had the highest parasite prevalence and abundance, respectively. These authors suggested that the more sedentary lifestyle of these females favors infection with directly transmitted nematodes (Rossin et al., 2010). Indeed, the burrow systems occupied by male B. suillus are significantly larger than those of their female conspecifics (Thomas et al., 2009). Hence, a similar explanation could apply to our study species. The observed effect of sex class on $L$. bathyergi abundance is probably also responsible for the significant effect of body length on infestation with this parasite as a result of the sexual dimorphism in body size.

We thank Prof. Jenny U. M. Jarvis for making the samples accessible. The study was funded by a Research Fellowship of the University of Pretoria to HL and the DST-NRF South African Research Chair for Behavioural Ecology and Physiology to NCB. The study was approved by the Animal Ethics Committee of the University of Pretoria (AUCC 040702-015). 


\section{LITERATURE CITED}

Bennett, N. C., and C. G. Faulkes. 2000. African mole-rats-Ecology and eusociality. Cambridge University Press, Cambridge, U.K., $273 \mathrm{p}$.

De GraAFF, G. 1964. On the parasites associated with the Bathyergidae. Koedoe 7: 113-123.

Folstad, I., AND A. J. Karter. 1992. Parasites, bright males, and the immunocompetence handicap. American Naturalist 139: 603-622.

Froeschke, G., R. Harf, S. Sommer, and S. Matthee. 2010. Effects of precipitation on parasite burden along a natural climatic gradient in southern Africa-Implications for possible shifts in infestation patterns due to global changes. Oikos 119: 1029-1039.

GARDNER, S. L. 1985. Helminth parasites of Thomomys bulbivorus (Richardson) (Rodentia: Geomyidae), with the description of a new species of Hymenolepis (Cestoda). Canadian Journal of Zoology 63: $1463-1469$.

Hafner, M. S., J. W. Demastes, and T. A. Spradling. 2000. Coevolution and subterranean rodents. In Life underground. The biology of subterranean rodents, E. A. Lacey, J. L. Patton, and G. N. Cameron (eds.). University of Chicago Press, Chicago, Illinois, p. 370-388.

Hart, L., M. J. O’Riain, J. U. M. Jarvis, and N. C. Bennett. 2006. Is the Cape dune mole-rat, Bathyergus suillus (Rodentia: Bathyergidae), a seasonal or aseasonal breeder? Journal of Mammalogy 87: 10781085.

INGLIS, W. G. 1991. Mammalakis n. g. and Mammalakinae n. subfam. (Nematoda: Heterakoidea: Kiwinematidae). Systematic Parasitology 20: 89-95.

KLeIN, S. L. 2004. Hormonal and immunological mechanisms mediating sex differences in parasite infection. Parasite Immunology 26: 247264

Modrý, D., M. Jirku, and R. Sumbera. 2005. Three new species of Eimeria (Apicomplexa: Eimeriidae) from the silvery mole rat
Heliophobius argenteocinereus Peters, 1846 (Rodentia: Bathyergidae) from Malawi. Journal of Parasitology 91: 1200-1203.

Moore, S. L., AND K. WiLSON. 2002. Parasites as a viability cost of sexual selection in natural populations of mammals. Science 297: 2015-2018.

OrtLepp, R. J. 1939. South African helminths, Part IV-Some helminths, chiefly from rodents. Onderstepoort Journal of Veterinary Research 12: $75-101$.

Poulin, R. 1996. Sexual inequalities in helminth infections: A cost of being male? American Naturalist 147: 287-295.

- 2007. Evolutionary ecology of parasites. Princeton University Press, Princeton, New Jersey, p. 134-159.

Rossin, M. A., AND A. I. MaliziA. 2002. Relationship between helminth parasites and demographic attributes of a population of the subterranean rodent Ctenomys talarum (Rodentia: Octodontidae). Journal of Parasitology 88: 1268-1270.

, - J. T. Timi, And R. Poulin. 2010. Parasitism underground: Determinants of helminth infections in two species of subterranean rodents Octodontidae). Parasitology 137: 1569-1575.

Scantlebury, M., M. Maher Mcwilliams, N. J. Marks, J. T. A. Dick, H. Edgar, AND H. Lutermann. 2010. Effects of life history traits on parasitism in Grey squirrels (Sciurus carolinensis). Journal of Zoology 282: 246-255.

Skinner, J. D., And C. T. Chimimba. 2005. The mammals of the southern African subregion, 3rd ed. Cambridge University Press, Cambridge, U.K., $814 \mathrm{p}$.

Tenora, F., V. Barus, M. Prokes, R. Sumbera, and B. Koubkova. 2003. Helminths parasitizing the silvery mole-rat, Heliophobius argenteocinereus (Rodentia: Bathyergidae) from Malawi. Helminthologia 40: $153-160$.

Thomas, H. G., P. W. Bateman, S. C. Le Comber, N. C. Bennett, R. W. Elwood, and M. Scantlebury. 2009. Burrow architecture and digging activity in the Cape dune mole-rat. Journal of Zoology 279: 277-284. 